\title{
A New Adaptive Anti-Windup Controller for Wind Energy Conversion System Based on PMSG
}

\author{
Ed-dahmani Chafik, Mahmoudi Hassane, Bakouri Anass, and El Azzaoui Marouane
}

Power Electronics and Control Laboratory, Electric Department, Mohammed V University, Morocco

\section{Article Info \\ Article history: \\ Received Aug 10, 2017 \\ Revised Nov 27, 2017 \\ Accepted Aug 6, 2018}

\section{Keyword:}

Anti-windup controller

PI controller

PMSG

WECS

\section{Corresponding Author:}

Ed-dahmani Chafik

Power Electronics and Control laboratory of Mohammadia school of engineers,

Mohammed V University, Rabat, Morocco

$+212674343036$

Email: chafik.eddahmani@research.emi.ac.ma

\begin{abstract}
In this paper, an adaptive anti-windup control strategy for permanent magnet synchronous generator dedicated for wind energy conversion systems. The proposed control has the advantage to suppress the performance deterioration caused by the overshooting phenomenon, and optimize the controller gains using the particle swarm optimization algorithm. The scheme of the speed controller is implemented on field orientation control in the generator side converter. A simulation of the proposed scheme is carried out in SIMULINK-MATLAB in order to evaluate the effectiveness of the control against the saturation and the parameter optimization.
\end{abstract}

Copyright (C) 2018 Insitute of Advanced Engineering and Science. All rights reserved.

\section{INTRODUCTION}

In the last decades, there has been a growing interest in wind turbines. Electrical generators and control strategies should respond to the needs of wind power applications. The permanent magnet synchronous generator (PMSG) and doubly fed induction generator (DFIG) are widely used in wind energy conversion systems (WECS) because they offer the possibility to work with variable wind speed [1]. Also, they can offer an improvement on production of wind energy, and the ability to achieve maximum energy conversion efficiency.

Comparing to doubly fed induction generator (DFIG), the PMSG can provide a high-efficiency and high reliability power generation, low maintenance required, and the electrical losses in the rotor are eliminated [2],[3]. Due to the mentioned advantages, the PMSG becomes an interesting solution for wind turbine applications. For a special architecture with a high number of poles pairs, the PMSG offers the possibility to eliminate the gearbox system as shown in Figure 1, that allows a higher efficiency. Several authors [4],[5] have discussed about the Variable wind speed conversion systems based on PMSG.

The conventional control strategy of PMSG is based on field oriented control (FOC) with PI controller [6]. This controller is easy to apply, and present a good performance in linear region [7],[8]. But, it suffers from non-linear effects such as saturation, when the saturation is neglected in the design phase it causes instability during closed-loop where the output system response takes a long time to stabilize in the steady state. In other words, this phenomenon is caused by the windup integrator contained in the PI controller, which keeps integrating the tracking error even if the input is saturating [9]-[10].

In order to overcome the windup phenomenon, several researches have proposed anti-windup techniques to deal with input saturation, where some proposals involve a complicated design [11],[12]. Thus, the average strategy to handle the integrator windup by tuning the controller disregarding the saturation caused by the integrator, and then adds an anti-windup compensator to avoid performance graduation [13]. Basically, the classical anti-windup strategies come with two different approaches, namely, conditional integration and tracking back-calculation.

In this paper, the speed control is based on adaptive anti-windup PI controller. The adaptation controller gains are gotten with search technique known as Particle Swarm Optimization technique (PSO), this technique was developed by Eberhart and Kennedy in 1995 [14],[15]. This technique is an optimization tool based on population, 
and the system is initialized with a population of random solutions and can search for optima by the updating of generations. The PSO algorithm has been used in power system for tuning control purpose in [16],[17],[18].

The aim of this paper is to implement, discuss and compare the racking performance of adaptive anti-windup speed controller with conventional linear PI. The proposed scheme of anti-windup eliminates the overshooting with a simple structure existing in PI controllers, and guarantees the independence between the desired performance and operating conditions. The simulation is realized with Simulink in order to verify the performance improvement comparing to conventional PI controller.

\section{MODELING THE WECS CONCEPTS}

\subsection{Wind turbine model}

A wind turbine is composed of many parts to convert a kinetic-to-electrical energy. The mechanical power and torque delivered by a wind turbine is given by (1) and (2).

$$
\begin{gathered}
P_{t}=0.5 \rho C_{p} \pi R^{2} v^{3} \\
T_{t}=0.5 \rho C_{p} \pi R^{2} \frac{v^{3}}{w_{t}} \\
C_{p}=0.5\left(\frac{116}{\lambda_{i}}-0.4 \beta-5\right) \cdot \exp \left(\frac{-21}{\lambda_{i}}\right)+0.0068 \lambda
\end{gathered}
$$

With: $\frac{1}{\lambda_{i}}=\frac{1}{\lambda+0.08 \beta}-\frac{0.035}{1+\beta^{3}}$

$\rho$ is the air density, $R$ is the blade radius, $v$ and $w_{t}$ are respectively the wind and turbine speed, $C_{p}$ is the power coefficient, $P_{t}$ is the turbine power, and $T_{t}$ is the turbine torque. The tip speed ratio (TSR: $\lambda$ ) is an important parameter in wind energy systems. It is defined as the ratio of the blade speed to the speed of incoming wind.

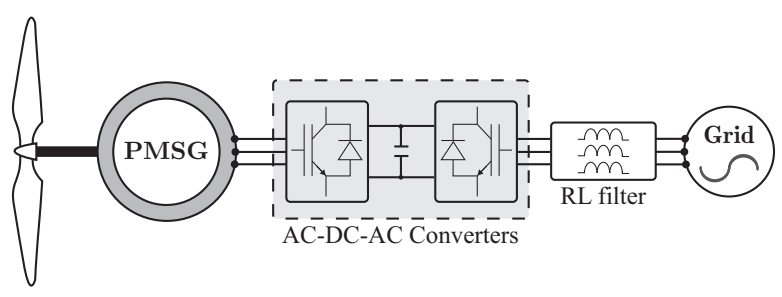

Figure 1. WECS based on direct drive PMSG.

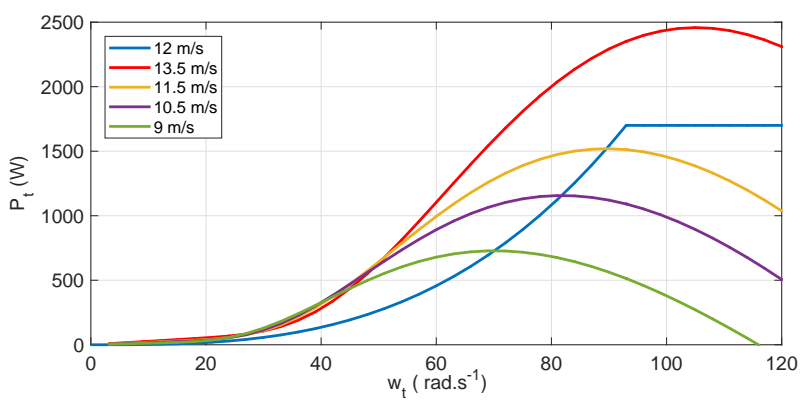

Figure 2. Turbine power evolution curve.

\subsection{PMSG Model}

Similarly to the induction generator (IG), the construction of the stator in PMSG is essentially the same. On the other side, the rotor magnetic flux is constant and generated by permanent magnets [19]. Also, depending on magnets architecture, the PMSG can be classified into surface-mounted and inset PM generators. The mathematical model of PMSG in synchronous rotating dq-reference is given by the following equations.

$$
\begin{array}{r}
\left\{\begin{array}{l}
V_{s d}=-R_{s} \cdot i_{s d}-L_{d} \frac{d i_{d}}{d t}+w_{r} L_{q} \cdot i_{s q} \\
V_{s q}=-R_{s} \cdot i_{s q}-L_{q} \frac{d i_{q}}{d t}-w_{r} L_{d} \cdot i_{s d}+w_{r} \phi_{f}
\end{array}\right. \\
T_{e}=\frac{3 P}{2}\left(\left(L_{d}-L_{q}\right) i_{s d} \cdot i_{s q}+\phi_{f} \cdot i_{s q}\right) \\
J \frac{d w_{m}}{d t}=T_{t}-T_{e}-B w_{m}
\end{array}
$$

Where, $R_{s}$ is the stator resistance, $L_{d q}$ are the inductances in dq-reference, $\phi_{f}$ is the PM-flux, $P$ is the pole pair number, $w_{r}$ and $w_{m}$ are electrical and mechanical speed, $V_{d q}, I_{d q}$ are the stator voltages and currents components in dq-reference, $T_{e}$ and $T_{t}$ are respectively the electromagnetic and turbine torque, $J$ and $B$ are respectively the equivalent system inertia and viscous damping. 
The equations (4) represent the electrical behavior of the PMSG which gives the possibility to control the dq-currents components. Also, the speed controller is based on (6). It should be noted that the electromagnetic torque $T_{e}$ may be controlled directly by the quadrature current component in case of surface mounted PM or zero direct current control (ZDC). Then, the expression of $T_{e}$ is given by (7).

$$
T_{e}=\frac{3 P}{2} \phi_{f} \cdot i_{s q}=K_{t} \cdot i_{s q}
$$

\section{WECS CONTROL STRATEGIES}

\subsection{Wind turbine control}

The purpose by turbine control is to produce a maximum power, this is achieved for a particular value of power coefficient, called $C_{p-\max }$, the maximal power coefficient is set to 0.48 , and it is given for a specified TSR $\lambda_{\text {opt }}=8.1$ with pitch angle $\beta=0$. The maximum power operation can be achieved with optimal torque control according to (9).

$$
\begin{array}{r}
\lambda_{o p t}=\frac{R . w_{m-o p t}}{v} \\
T_{t-o p t}=0.5 \rho C_{p-\max } \pi R^{5} \frac{w_{t-o p t}^{2}}{\lambda_{o p t}}
\end{array}
$$

Also, to guarantee the safety working of the turbine against strong wind, a pitch angle controller is implemented in Figure 4. The working principle of this controller is by comparing the generated power $P_{t}$ with the nominal power, then it generates a pitch angle response.

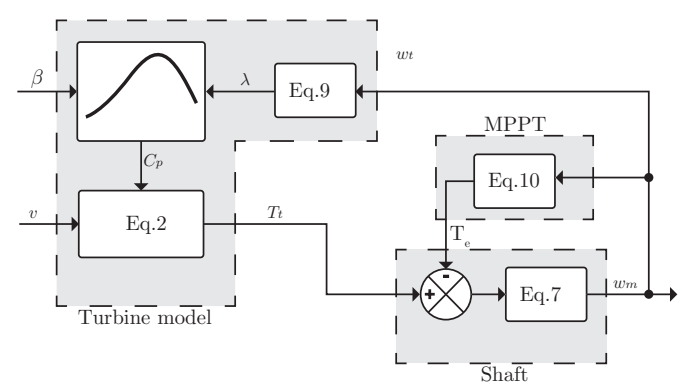

Figure 3. Turbine model diagram scheme.

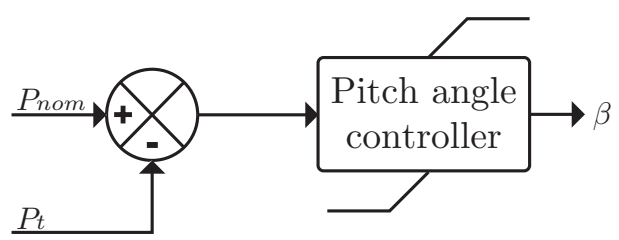

Figure 4. pitch angle controller scheme

\subsection{Speed control of PMSG}

The windup phenomenon comes when the output current command of the speed controller is limited to a maximum value, and the integral component becomes very large because is not compatible with the plant input. Which causes a large overshoot and slow settling time in the speed response.

In this paper, the speed-loop controller has been designed using an adaptive gains anti-windup algorithm. It has an advantage to eliminate the overshooting phenomenon during operation that can deteriorate the power generation performance. The aim of anti-windup control for nonlinear system with saturating actuators is to modify the control in order to limit the overshoot. 
The proposed anti-windup strategy by [7] as shown in fig.5 can switch between the P and PI modes according to the working states. For the PI mode, it is necessary to initialize the integrator, and in case of P mode the initial value of $i_{s q-i}(0)$ is inserted, where the PI mode can utilize this value. A low pass filter is used to avoid an abrupt change of current by loading the initial value $i_{s q-i}(0)$ in the LPF.

\subsection{Closed loop identification}

According to the mechanical equations of the PMSG (6),(7), and for simplicity, the viscous damping B is neglected, the new expression of mechanical equation of WECS is given as follow

$$
J \frac{d w_{m}}{d t}=K_{t} . i_{s q}-T_{t}
$$

The quadrature stator current component $\left(i_{s q}\right)$ can be written for the PI controller as (12).

$$
\left\{\begin{array}{l}
i_{s q}=i_{s q-i}+i_{s q-p} \\
i_{s q-p}=K_{p}\left(w_{m-r e f}-w_{m}\right) \\
i_{s q-i}=\frac{K_{i}}{s}\left(w_{m-r e f}-w_{m}\right)+\frac{i_{s q}(0)}{s}
\end{array}\right.
$$

Where, $w_{m-r e f}$ is the reference speed of the PMSG which is the optimal speed derived from the MPPT of turbine, $i_{s q-p}$ and $i_{s q-i}$ are the proportional and integral components of $i_{s q}, K_{p}$ and $K_{i}$ are the PI controller gains. By implementing the Laplace transform on (10) and substituting by (11), the transfer function of the closed loop for the mechanical is expressed by (12).

$$
J\left(s w_{m}-w_{m}(0)\right)=\frac{-T_{t}}{s}+K_{t}\left[\left(K_{p}+\frac{K_{i}}{s}\right)\left(w_{m-r e f}-w_{m}\right)+\frac{i_{s q}(0)}{s}\right]
$$

$w_{m}(0)$ and $i_{s q}(0)$ denotes the initial states values of mechanical speed and quadrature stator current. Then, the mechanical speed $w_{m}(s)$ can expressed as a function of the input arguments shown in (13).

$$
w_{m}(s)=\left[\begin{array}{c}
\frac{K_{i} \cdot K_{t}+s K_{t} \cdot K_{p}}{J s^{2}+K_{t} K_{p} \cdot s+K_{t} K_{i}} \\
\frac{K_{t}}{J s^{2}+K_{t} K_{p} \cdot s+K_{t} K_{i}} \\
\frac{J_{s}}{J s^{2}+K_{t} K_{p} \cdot s+K_{t} K_{i}} \\
\frac{-1}{J s^{2}+K_{t} K_{p} \cdot s+K_{t} K_{i}}
\end{array}\right]^{T} \cdot\left[\begin{array}{c}
W_{m-r e f} \\
i_{s q-i}(0) \\
w_{m}(0) \\
T_{t}
\end{array}\right]
$$
expressed as:

In the steady state, according to (10) and (11), the proportional and integral terms of quadrature current are

$$
\left\{\begin{array}{l}
i_{s q-p s t e a d y}=0 \\
i_{s q-i s t e a d y}=\frac{T_{t}}{K_{t}}
\end{array}\right.
$$

When the PI mode is activated, the initial integral term of $i_{s q}$ is defined by (15).

$$
i_{s q-i}(0)=\frac{T_{t}}{K_{t}}-m\left(w_{m-r e f}-w_{m}(0)\right)
$$

The first term of (15) signify the required current at steady state according to (14), for the second term it is assigned to the compensation term for the overshoot. With $\mathrm{m}$ is the anti-windup controller gains. Substituting (15) in (13).

$$
w_{m}(s)=\left[\begin{array}{ll}
\frac{K_{t}\left(K_{i}+s\left(K_{p}-m\right)\right)}{J s^{2}+K_{t} K_{p} \cdot s+K_{t} K_{i}} & \frac{K_{t} \cdot m+J . s}{J s^{2}+K_{t} K_{p} \cdot s+K_{t} K_{i}}
\end{array}\right] \cdot\left[\begin{array}{c}
W_{m-r e f} \\
w_{m}(0)
\end{array}\right]
$$

Then, (16) can be simplified during the PI mode to the final expression as:

$$
w_{m}(s)-\frac{w_{m}(0)}{s}=\frac{K_{t}\left(K_{i}+s\left(K_{p}-m\right)\right)}{J s^{2}+K_{t} K_{p} . s+K_{t} K_{i}} \cdot\left(w_{m-r e f}-\frac{w_{m}(0)}{s}\right)
$$




\subsection{Controller design}

In order to establish a good performance for speed controller, the anti-windup controller gain $\mathrm{m}$ should be determined in the PI mode. According to (12), the transfer function can be rewritten as

$$
H(s)=\frac{K_{t}\left(K_{i}+s\left(K_{p}-m\right)\right)}{J s^{2}+K_{t} K_{p} \cdot s+K_{t} K_{i}}=-\frac{p_{1} \cdot p_{2}}{z} \cdot \frac{s-z}{\left(s-p_{1}\right)\left(s-p_{2}\right)}
$$

Where $z$ is the zero, and $p_{1,2}$ are the poles of transfer function.

$$
\left\{\begin{array}{l}
z=-\frac{K_{i}}{K_{p}-m} \\
p_{1,2}=\frac{-K_{t} \cdot K_{p} \pm \sqrt{\left(K_{t} \cdot K_{p}\right)^{2}-4 J \cdot K_{t} \cdot K_{i}}}{2 J}
\end{array}\right.
$$

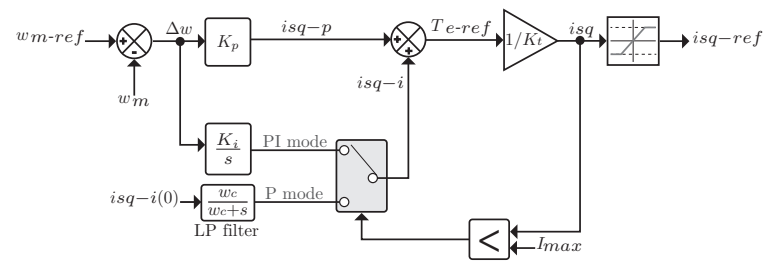

Figure 5. Diagram scheme of the proposed anti-windup speed controller.

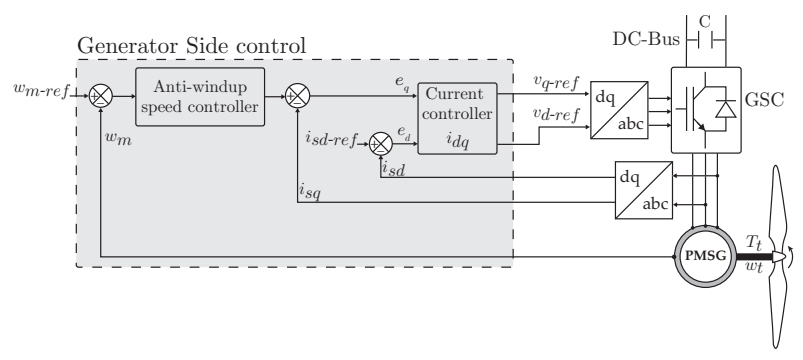

Figure 6. Global structure of the generator side based on the proposed control for the mechanical speed.

As mentioned in [7] and [9], the pole is a function of PI gains, and the zero-location determined by the antiwindup and PI gains. In order to simplify the transfer function to first order as shown in (21), it is assumed that $z=p_{1}$ in such away $\left|p_{1}\right|<\left|p_{2}\right|$, which represents a first order low pass filter without saturation. In that case, the anti-windup gain is given by (20). If the gain is smaller than the specified value, a higher overshoot is provided. Else, a large value can result a slow response.

$$
\begin{aligned}
& m=K_{p}+\frac{K_{i}}{p_{1}} \\
& H(s)=\frac{p_{2}}{p_{2}-s}
\end{aligned}
$$

The next step is to determine the initial value of the input arguments. In transition state between the $\mathrm{P}$ mode to PI mode, the initial integral term of q-axis current component is given as follow:

$$
i_{s q-i}(0)=-I_{\max }-K_{p}\left(w_{m-r e f}-w_{m}(0)\right)
$$

Where $I_{\max }$ is the maximum limited current. Also, according to (10), the turbine torque can be expressed by in steady state. Using (15) and (22), the new expression of $i_{s q-i}(0)$ is given by

$$
i_{s q-i}(0)=\frac{K_{p} \cdot i_{s q-i s t e a d y}+m \cdot I_{\max }}{K_{p}-m}
$$

When the $\mathrm{P}$ mode is selected, the initial integral current $i_{s q-i}(0)$ is generated by the low-pass filter. The initial mechanical speed $w_{m}(0)$ can be expressed as follow

$$
w_{m}(0)=w_{m-r e f}+\frac{i_{s q-i s t e a d y}+I_{\max }}{K_{p}-m}
$$

\subsection{Particle Swarm Optimization}

In the previous part, the controller has been designed. The anti-windup controller parameters gains, as $K_{p}$, $K_{i}$ and $m$ determine the performance system. The selection of parameters is a task that can be difficult. In order to guarantee a fast-dynamic response and optimal control, PSO comes to solve the problem of parameters estimation. PSO derived from social, psychological theory. It imitates the natural process of group communication to share 
individual experience flocking, migrating, or hunting. Basically, it searches for the optimal solution from a population of moving particles. In PSO, starting with a randomly initialized population called a swarm, each member called particle flies through the searching space, where is positioned by $x_{i}$ vector, evaluating the fitness, and remember the best position $x_{\text {gbest }}$ on which it has the best fitness. This information is shared by all particles and adjust their positions $x_{i}$, and velocities $v_{i}$ according to the information. The velocity adjustment is based on the historical behaviors of the particles themselves and their companions. The particles tend to fly better to best the positions [17],[18]. The velocity and current position respectively of every particle are evaluated by (25) and (26).

$$
v_{i}(t+1)=w \cdot v_{i}(t)+a\left[r_{1}\left(x_{p b e s t}-x_{i}(t)\right)+r_{2}\left(x_{g b e s t}-x_{i}(t)\right)\right]
$$

$$
x_{i}(t+1)=x_{i}(t)+v_{i}(t)
$$

Where, $t$ is time step, $w$ the inertia weight factor, $a$ acceleration constant, $r_{1}, r_{2}$ are random functions in the range of [0,1], $x_{i}$ the position of $i^{t h}$ particle, $x_{p b e s t}$ the best previous position of $i^{t h}$ particle, $x_{g b e s t}$ the position of best particle among the entire population, and $v_{i}$ the velocity for the $i^{\text {th }}$ particle.

The adaptive weighted PSO has been proposed in (27) to improve the reaching capability.

$$
a=a_{0}+\frac{t}{N_{t}}
$$

With $N_{t}$ indicate the iterations number, $t$ is the current step, and $a_{0}$ is a constant in [0.5,1]. It should be noted that the inertia weight changes at every step by (28).

$$
w=w_{0}+r_{3}\left(1-w_{0}\right)
$$

With, $w_{0}$ is a positive constant chosen in [0.5,1], and $r_{3}$ is a random function in the range of [0,1].

\section{SIMULATION RESULTS}

To verify the effectiveness of the PI anti-windup speed controller, a simulation of the proposed scheme is carried out in Simulink. The PMSG and turbine data are listed in Table 1.In order to evaluate the controller performance in extreme cases, a step change is applied for the speed reference and load torque. Figure 7 shows a comparison of the tracking performance of mechanical speed responses by the conventional PI and anti-windup controllers with different iteration numbers for a step changing speed response $70 \mathrm{rad} / \mathrm{s} \rightarrow 157 \mathrm{rad} / \mathrm{s} \rightarrow 120 \mathrm{rad} / \mathrm{s}$. By comparing the speed responses, in the adaptive anti-windup controller, the saturation input is limited which can guarantee a better stability and high tracking performance. Also, compared to the conventional PI controller, the PSO improve the controller performance, by selecting the optimal gains. With the proposed method, the steady-state is quickly established for an optimal value of the iterations number.Therefore, the anti-windup controller provides the optimal dynamic performance in term of convergence, saturation, and robustness compared to conventional PI controller. The simulation of generator side converter for the WECS is based on the wind speed profile of Figure 8, it should be noted that the nominal speed of the wind is chosen $v_{n o m}=12 \mathrm{~m}_{\mathrm{s}} \mathrm{s}^{-1}$. From Figure 9(a)-9(b), the power coefficient and tip speed ratio-TSR are maintained at their optimal values by the MPPT control. The pitch angle controller is activated when the wind speed exceeds the nominal speed. Then, the power coefficient and tip speed ratio are decreased in order to kept the extracted power at the nominal value. Figure 9(c) represents the pitch angle controller response for variable wind speed. The mechanical turbine power is illustrated in Figure 9(d) changed according to the wind speed variation, also it is maintained in nominal state when the pitch angle controller is activated. 


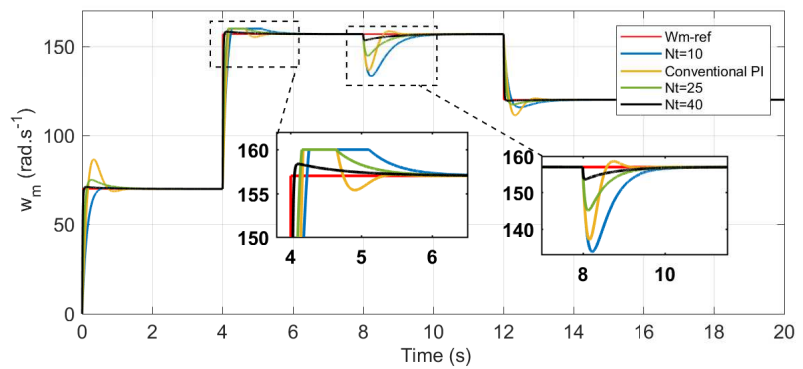

Figure 7. Comparison Simulation responses for conventional PI speed-controller and the speed anti-windup controller with different iterations number $N_{t}$

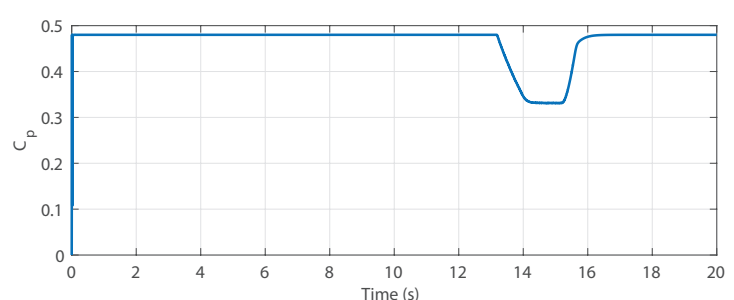

(a) Power coefficient response

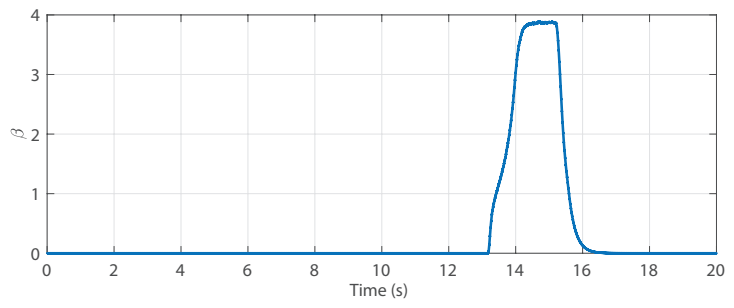

(c) Pitch angle response

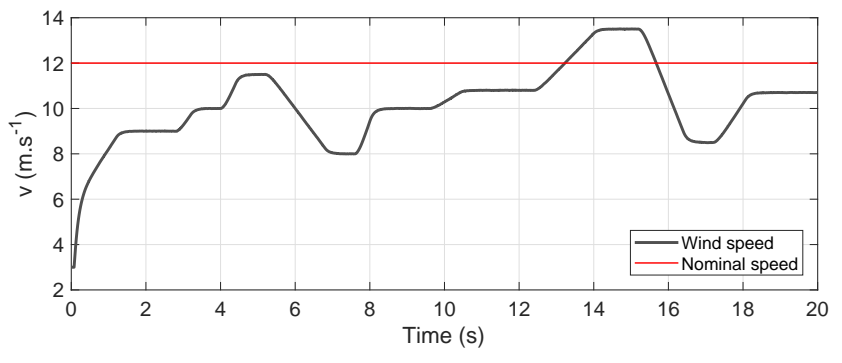

Figure 8. wind speed profile.

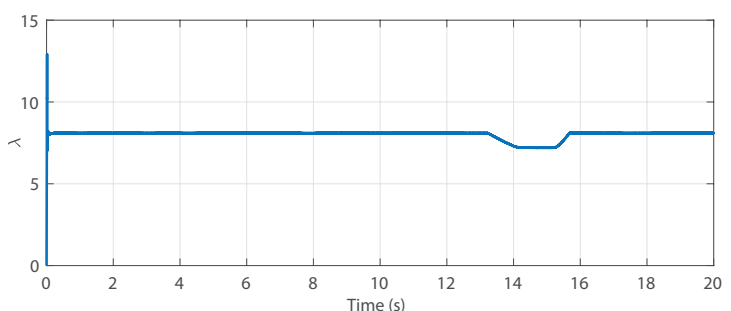

(b) Tip speed ratio response

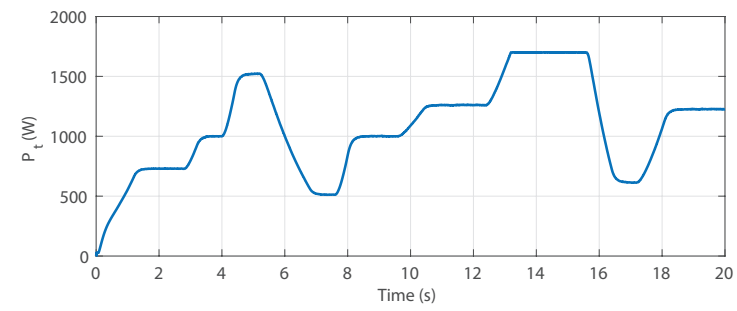

(d) Turbine power response

Figure 9. Turbine dynamic performance using the MPPT and pitch angle controllers

Table 1. Turbine and PMSG data

\begin{tabular}{lcr}
\hline Nominal power & $P_{n}$ & $1.7 \mathrm{~kW}$ \\
Turbine radius & $R$ & $1.04 \mathrm{~m}$ \\
Air density & $\rho$ & $1.22 \mathrm{~kg} / \mathrm{m}^{3}$ \\
Gearbox gain & $G$ & 1.7 \\
Equivalent system inertia & $\mathrm{J}$ & $0.35 N . m . \mathrm{rad}^{-1} . \mathrm{s}^{2}$ \\
Maximum power coefficient & $C_{p-\max }$ & 0.48 \\
Optimal speed ratio & $\lambda_{\text {opt }}$ & 8.1 \\
Nominal current & $I_{n o m}$ & $5 \mathrm{~A}$ \\
Stator resistance & $R_{s}$ & $2.7 \Omega$ \\
Stator inductance & $L_{d, q}$ & $3.1 \mathrm{mH}$ \\
PM flux & $\phi_{f}$ & $0.341 \mathrm{~Wb}$ \\
Pole pairs number & $P$ & 4 \\
Nominal speed & $w_{n o m}$ & $157.1 \mathrm{rad} . \mathrm{s}^{-1}$ \\
Nominal frequency & $f r$ & $100 \mathrm{~Hz}$ \\
\hline
\end{tabular}

Figure 10(a) shows the high tracking performance of mechanical speed response of the proposed controller under a variable turbine speed, it should be noted that the refence speed is given by the MPPT bloc controller. Also, the mechanical speed response is stable and tracks the reference value by using the selected value of the PSO algorithm. 
In Figure 10(b), the electromagnetic torque is identical to the reference value. When, the pitch control is activated the PMSG speed and electromagnetic torque are kept at the nominal values, which implies that the extracted power is maximal. Figure 10(c) shows current responses in dq frame. The FOC with ZDC is applied, where the reference current component of d-axis is set to zero $\left(i_{s d-r e f}=0\right)$ as shown in Figure 6, and the quadrature current is proportional to the turbine torque as mentioned in (7). For the three-phase stator current response is shown in Figure 10(d). Where, the current amplitude and frequency are proportionals respectively to electromagnetic torque $T_{e}$ and generator velocity $w_{m}$.

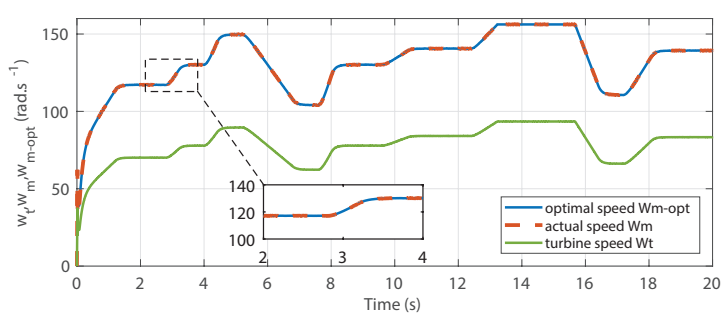

(a) Mechanical speed response of PMSG

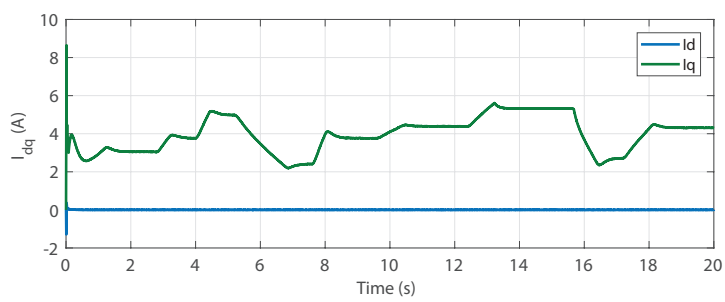

(c) Current response in dq plan

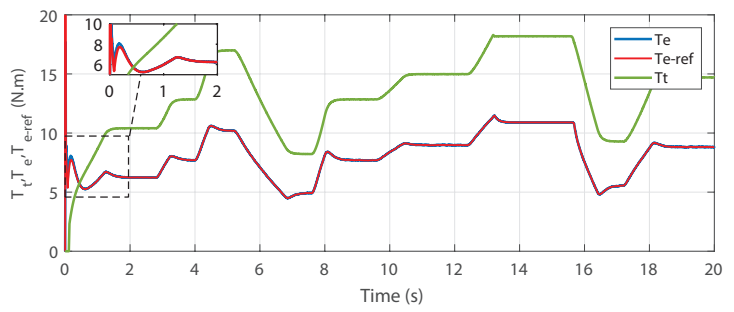

(b) Electromagnetic torque response

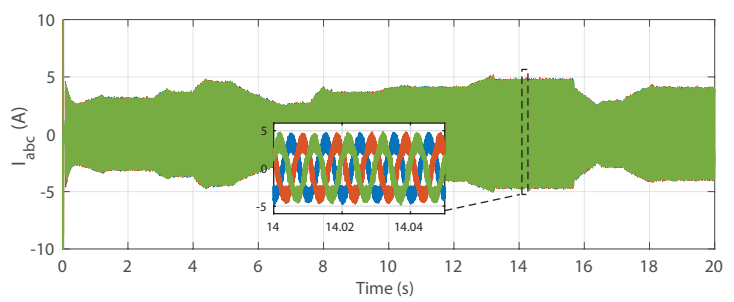

(d) Stator current response

Figure 10. PMSG dynamic performance with the anti-windup speed controller

\section{CONCLUSION}

The adaptive anti-windup was proposed in this paper to replace the conventional PI controller for the speed controller in the direct drive PMSG field oriented control. The initial values of the integrator current and mechanical speed are determined. The PSO algorithm is used to estimate the optimal parameters of the proposed controller, which gives a high tracking and dynamic performance, and fast response with least overshoot. The anti-windup controller is designed to give a best tracking speed comparing to the conventional linear PI controllers. The proposed control is implemented for the speed-loop. The simulation results confirm the effectiveness of the anti-windup controller regarding the saturation phenomenon and fast responses.

\section{REFERENCES}

[1] I. Boldea, Variable Speed Generators, Nov. 2005.

[2] A. Bakouri, H. Mahmoudi, and A. Abbou, "Intelligent Control for Doubly Fed Induction Generator Connected to the Electrical Network," International Journal of Power Electronics and Drive Systems (IJPEDS), vol. 7, no. 3, pp. 688-700, Sep. 2016.

[3] M. E. Azzaoui, H. Mahmoudi, and K. Boudaraia, "Backstepping Control of Wind and Photovoltaic Hybrid Renewable Energy System," International Journal of Power Electronics and Drive Systems (IJPEDS), vol. 7 , no. 3, pp. 677-687, Sep. 2016.

[4] H. Polinder, F. F. A. v. d. Pijl, G. J. d. Vilder, and P. J. Tavner, "Comparison of direct-drive and geared generator concepts for wind turbines," IEEE Transactions on Energy Conversion, vol. 21, no. 3, pp. 725-733, Sep. 2006.

[5] M. Chinchilla, S. Arnaltes, and J. C. Burgos, "Control of permanent-magnet generators applied to variable-speed wind-energy systems connected to the grid," IEEE Transactions on Energy Conversion, vol. 21, no. 1, pp. 130135, Mar. 2006.

[6] J. Liang and B. Whitby, "Field Oriented Control of a Permanent Magnet Synchronous Generator for use in a Variable Speed Tidal Stream Turbine," in Universities' Power Engineering Conference (UPEC), Proceedings of 2011 46th International, Sep. 2011, pp. 1-6. 
[7] J. W. Choi and S. C. Lee, “Antiwindup Strategy for PI-Type Speed Controller," IEEE Transactions on Industrial Electronics, vol. 56, no. 6, pp. 2039-2046, Jun. 2009.

[8] H. B. Shin and J. G. Park, "Anti-Windup PID Controller With Integral State Predictor for Variable-Speed Motor Drives," IEEE Transactions on Industrial Electronics, vol. 59, no. 3, pp. 1509-1516, Mar. 2012.

[9] S. Tarbouriech and M. Turner, "Anti-windup design: an overview of some recent advances and open problems," IET Control Theory Applications, vol. 3, no. 1, pp. 1-19, Jan. 2009.

[10] R. J. Wai, J. D. Lee, and K. L. Chuang, "Real-Time PID Control Strategy for Maglev Transportation System via Particle Swarm Optimization," IEEE Transactions on Industrial Electronics, vol. 58, no. 2, pp. 629-646, Feb. 2011.

[11] F. C. Ferreira, T. R. Nascimento, M. F. Santos, N. F. S. Bem, and V. C. Reis, "Anti wind-up techniques applied to real tank level system performed by PI controllers," in 2016 20th International Conference on System Theory, Control and Computing (ICSTCC), Oct. 2016, pp. 263-268.

[12] L. Meng and M. Li, "A new antiwindup pi controller for direct torque control system," TELKOMNIKA Indonesian Journal of Electrical Engineering, vol. 12, no. 7, pp. 5268-5274, 2014.

[13] A. Visioli, "Modified anti-windup scheme for PID controllers," IEE Proceedings - Control Theory and Applications, vol. 150, no. 1, pp. 49-54, Jan. 2003.

[14] R. Eberhart and J. Kennedy, "A new optimizer using particle swarm theory," in , Proceedings of the Sixth International Symposium on Micro Machine and Human Science, 1995. MHS '95, Oct. 1995, pp. 39-43.

[15] Y. Shi and R. Eberhart, "A modified particle swarm optimizer," in 1998 IEEE International Conference on Evolutionary Computation Proceedings. IEEE World Congress on Computational Intelligence (Cat. No.98TH8360), May 1998, pp. 69-73.

[16] Y. d. Valle, G. K. Venayagamoorthy, S. Mohagheghi, J. C. Hernandez, and R. G. Harley, "Particle Swarm Optimization: Basic Concepts, Variants and Applications in Power Systems," IEEE Transactions on Evolutionary Computation, vol. 12, no. 2, pp. 171-195, Apr. 2008.

[17] W. Qiao, G. K. Venayagamoorthy, and R. G. Harley, "Design of Optimal PI Controllers for Doubly Fed Induction Generators Driven by Wind Turbines Using Particle Swarm Optimization," in The 2006 IEEE International Joint Conference on Neural Network Proceedings, 2006, pp. 1982-1987.

[18] M. Yang, X. Wang, and K. Zheng, "Adaptive backstepping controller design for permanent magnet synchronous motor," in 2010 8th World Congress on Intelligent Control and Automation, Jul. 2010, pp. 4968-4972.

[19] C. Ed-dahmani, H. Mahmoudi, and M. Elazzaoui, "Direct torque control of permanent magnet synchronous motors in MATLAB/SIMULINK," in 2016 International Conference on Electrical and Information Technologies (ICEIT), May 2016, pp. 452-457. 